\title{
Short-Term Efficacy and Safety of Secukinumab for Ankylosing Spondylitis: A Systematic Review and Meta-Analysis of RCTs
}

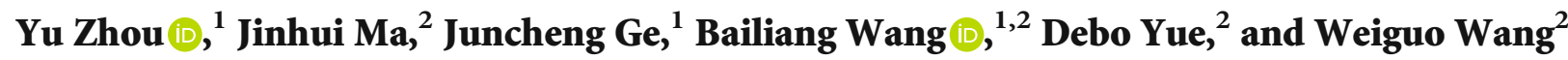 \\ ${ }^{1}$ Department of Orthopaedic Surgery, Peking University China-Japan Friendship School of Clinical Medicine, Beijing 100029, China \\ ${ }^{2}$ Department of Orthopaedic Surgery, Center for Osteonecrosis and Joint Preserving \& Reconstruction, China- \\ Japan Friendship Hospital, Beijing 100029, China
}

Correspondence should be addressed to Bailiang Wang; wang_orthopaedic@126.com

Received 27 May 2020; Accepted 23 July 2020; Published 28 October 2020

Academic Editor: Qingdong Guan

Copyright $\odot 2020$ Yu Zhou et al. This is an open access article distributed under the Creative Commons Attribution License, which permits unrestricted use, distribution, and reproduction in any medium, provided the original work is properly cited.

Secukinumab is a novel IL-17A inhibitor that has been confirmed to be effective for treating PsA and RA. Several studies have demonstrated that secukinumab also provides benefits for AS patients. Thus, we performed a meta-analysis of RCTs to evaluate the short-term efficacy and safety of secukinumab for the management of AS. The PubMed, Medline, Embase, Web of Science, and Cochrane Library databases were searched for RCTs published prior to March 2020 on the treatment of AS with secukinumab. The primary outcome was the ASAS20 response, and the secondary outcomes included the ASAS40 response, ASAS5/6 response, SF-36 PCS score, ASQoL score, and AEs. Dichotomous data were expressed as pooled RRs with 95\% CIs, while continuous data were expressed as pooled MDs with 95\% CIs. Subgroup analysis was conducted based on whether the AS patients previously underwent treatment with TNFi. A total of 4 RCTs with 1166 patients were included in our meta-analysis. At week 16, secukinumab $150 \mathrm{mg}$ yielded significant improvements in the clinical response and patient-reported outcomes for AS patients. There was no increased risk of AEs. Consistent results were detected in the meta-analysis of secukinumab $75 \mathrm{mg}$ versus a placebo. Furthermore, no significant difference was detected between the secukinumab $75 \mathrm{mg}$ group and secukinumab $150 \mathrm{mg}$ group. We concluded that secukinumab is effective for treating AS and generally well tolerated by AS patients in the short term, regardless of whether they previously underwent TNFi treatment. The superiority of secukinumab $150 \mathrm{mg}$ over secukinumab $75 \mathrm{mg}$ seems to be limited, since no significant difference in any endpoint was detected between the two groups.

\section{Introduction}

Ankylosing spondylitis (AS) is a chronic autoimmune inflammatory disease and a subtype of radiographic axial spondyloarthritis [1]. The prevalence of AS in the Chinese population is $0.29 \%$ and continues to increase; the ratio of males to females who are affected by this disease is $2.8: 1$ [2]. AS predominantly affects the spine and sacroiliac joints, causing chronic back pain, fatigue, and a loss of spinal mobility [3]. Without effective treatment, due to excessive bone regeneration and syndesmophyte formation, the gaps between joints gradually become filled, ultimately leading to ankylosis, deformities, a poor quality of life, and a substantial economic burden on patients and society $[4,5]$.

To date, the underlying mechanism of AS has not been identified completely. In recent years, published studies have uncovered several potential factors contributing to the occurrence of AS, such as genetic features, intestinal microbiomes, infections, as well as medication, and toxin exposure [6]. The HLA-B27 allele represents the strongest genetic factor, and there are four mainstream hypotheses attempting to illustrate its role in the pathogenesis of AS, including the IL-23/IL-17 axis theory [7]. Previous studies have demonstrated that AS patients exhibit increased IL-17 and IL-23 levels in the serum and synovial fluid $[8,9]$. This imbalance of the IL-17/IL-23 axis may lead to uncontrolled inflammation, joint destruction, and excessive bone formation, which can promote the progression of the disease $[4,10,11]$. In addition, the blockage of IL-17 has been proved to reduce cartilage destruction and bone erosion in collagen-induced arthritis models, which suggests that IL-17 should potentially be a target for the management of AS $[12,13]$. Taken together, these results suggest that 


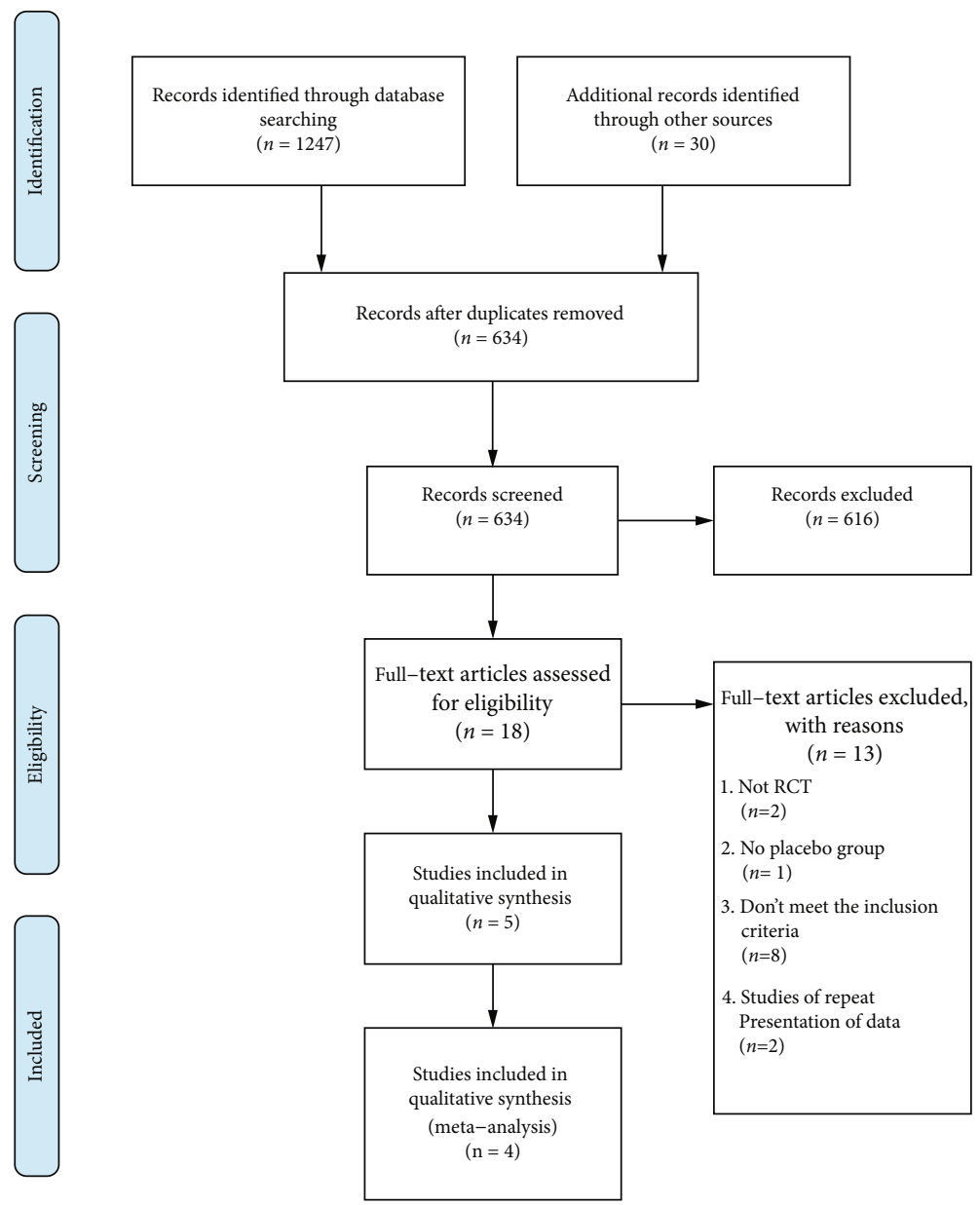

FIGURE 1: Flow chart of the literature search.

AS is an autoimmune disease caused by the interaction between host genetic features and environmental factors, and the IL-23/IL-17 axis plays a critical role in its pathogenesis.

Historically, the treatment of AS has been limited to nonsteroidal anti-inflammatory drugs (NSAIDs). The introduction of tumor necrosis factor inhibitors (TNFis) has opened a new chapter and driven significant advancements in the management of AS over the past 20 years [14]. However, TNFis have their own limitations since $40 \%$ of AS patients have failed to respond adequately [15]. Secukinumab is a novel IL-17A inhibitor that has been confirmed to be effective for treating psoriatic arthritis (PsA) and rheumatoid arthritis (RA) [16, 17]. Several randomized controlled trials (RCTs) and studies conducted in real-world settings have demonstrated that secukinumab also provides benefits for patients with AS [18-25]. However, its clinical application is limited because current evidence is not as robust as that for other therapies (NSAIDs and TNFis). Therefore, we conducted a meta-analysis of RCTs to evaluate the short-term efficacy and safety of secukinumab for treating AS.

\section{Materials and Methods}

This meta-analysis was performed in accordance with the Preferred Reporting Items for Systematic Reviews and
Meta-Analyses (PRISMA) reporting guidelines [26] for conducting meta-analyses of intervention trials.

2.1. Search Strategy. We searched PubMed, Medline, Embase, Web of Science, and Cochrane Library for available articles published prior to March 2020 on the treatment of AS with secukinumab. The search terms were as follows: "ankylosing spondylitis", "spondyloarthritis", "secukinumab", and "cosentyx". No publication status restrictions were applied. For this meta-analysis, we considered only studies published in English. Furthermore, we also searched the reference lists of review articles for potentially relevant trials.

2.2. Inclusion Criteria. The inclusion criteria were as follows: the patients were diagnosed with AS on the basis of the 1984 modified New York diagnostic criteria; at least one experimental group was treated with secukinumab, while the control group was treated with a placebo; the efficacy of secukinumab for the treatment of AS was assessed; the primary outcome was the proportion of patients who met the ASAS20 criteria at week 16 , and the secondary outcomes included the ASAS40 response rate, ASAS5/6 response rate, the change from baseline in the scores of the Short Form36 Physical Component Summary (SF-36 PCS), and Ankylosing Spondylitis Quality of Life Scale (ASQoL) at week 16. 
TABLE 1: Basic characteristics of all eligible studies.

\begin{tabular}{|c|c|c|c|c|c|c|c|c|c|}
\hline $\begin{array}{l}\text { ClinicalTrials.gov } \\
\text { numbers }\end{array}$ & $\begin{array}{l}\text { Study } \\
\text { (y) }\end{array}$ & Study design & Treatment & Samples & $\begin{array}{l}\text { Male } \\
N(\%)\end{array}$ & $\begin{array}{l}\text { Weight } \\
(\mathrm{kg})\end{array}$ & $\begin{array}{c}\text { Age } \\
\text { (years) }\end{array}$ & $\begin{array}{l}\text { Duration } \\
\text { of AS } \\
\text { (years) }\end{array}$ & Outcomes \\
\hline NCT01358175 & $\begin{array}{c}\text { Baeten } \\
(2015) \\
{[19]}\end{array}$ & $\begin{array}{l}\text { Randomized double-blind } \\
\text { placebo-controlled } \\
\text { multicenter phase } 3 \text { trials }\end{array}$ & $\begin{array}{l}\text { SEC } 75 \mathrm{mg} \\
\text { SEC } 150 \mathrm{mg} \\
\text { Placebo } \\
\text { MEASURE } 1\end{array}$ & $\begin{array}{l}124 \\
125 \\
122\end{array}$ & $\begin{array}{c}88 \\
(71) \\
84 \\
(67) \\
85 \\
(70)\end{array}$ & $\begin{array}{l}77.7 \pm 19.6 \\
74.7 \pm 16.2 \\
76.7 \pm 14.4\end{array}$ & $\begin{array}{l}42.3 \pm 13.2 \\
40.1 \pm 11.6 \\
43.1 \pm 12.4\end{array}$ & $\begin{array}{l}7.9 \pm 9.7 \\
6.5 \pm 6.9 \\
8.3 \pm 8.9\end{array}$ & $\begin{array}{l}\text { a b c d e f } \\
\text { at week } \\
16\end{array}$ \\
\hline NCT01649375 & $\begin{array}{c}\text { Baeten } \\
(2015) \\
{[19]} \\
\text { Sieper } \\
(2016) \\
{[22]}\end{array}$ & $\begin{array}{c}\text { Randomized } \\
\text { double-blind } \\
\text { placebo-controlled } \\
\text { multicenter phase } 3 \text { trials }\end{array}$ & $\begin{array}{l}\text { SEC } 75 \mathrm{mg} \\
\text { SEC } 150 \mathrm{mg} \\
\text { Placebo } \\
\text { MEASURE } 2\end{array}$ & $\begin{array}{l}73 \\
72 \\
74\end{array}$ & $\begin{array}{c}51 \\
(70) \\
46 \\
(64) \\
56 \\
(76)\end{array}$ & $\begin{array}{l}81.5 \pm 17.4 \\
82.3 \pm 18.0 \\
80.3 \pm 15.2\end{array}$ & $\begin{array}{l}44.4 \pm 13.1 \\
41.9 \pm 12.5 \\
43.6 \pm 13.2\end{array}$ & $\begin{array}{l}5.3 \pm 7.4 \\
7.0 \pm 8.2 \\
6.4 \pm 8.9\end{array}$ & $\begin{array}{l}\text { a b c d e f } \\
\text { at week } \\
16\end{array}$ \\
\hline NCT02008916 & $\begin{array}{c}\text { Pavelka } \\
(2017) \\
{[20]}\end{array}$ & $\begin{array}{c}\text { Randomized } \\
\text { double-blind } \\
\text { placebo-controlled } \\
\text { multicenter phase } 3 \text { trials }\end{array}$ & $\begin{array}{l}\text { SEC } 150 \mathrm{mg} \\
\text { SEC } 300 \mathrm{mg} \\
\text { Placebo } \\
\text { MEASURE } 3\end{array}$ & $\begin{array}{l}74 \\
76 \\
76\end{array}$ & $\begin{array}{c}46 \\
(62) \\
50 \\
(66) \\
40 \\
(53)\end{array}$ & $\begin{array}{l}80.3 \pm 19.2 \\
82.7 \pm 16.9 \\
79.0 \pm 15.5\end{array}$ & $\begin{array}{l}42.9 \pm 11.1 \\
42.1 \pm 11.8 \\
42.7 \pm 11.4\end{array}$ & $\begin{array}{l}6.0 \pm 7.2 \\
5.3 \pm 7.3 \\
5.2 \pm 6.4\end{array}$ & $\begin{array}{c}\text { a b c f } \\
\text { at week } \\
16\end{array}$ \\
\hline NCT02159053 & $\begin{array}{c}\text { Kivitz } \\
(2018) \\
{[21]}\end{array}$ & $\begin{array}{c}\text { Randomized } \\
\text { double-blind } \\
\text { placebo-controlled } \\
\text { multicenter phase } 3 \text { trials }\end{array}$ & $\begin{array}{c}\text { SEC } 150 \mathrm{mg} \\
\text { no load } \\
\text { SEC } 150 \mathrm{mg} \\
\text { load } \\
\text { Placebo } \\
\text { MEASURE } 4\end{array}$ & $\begin{array}{l}117 \\
116 \\
117\end{array}$ & $\begin{array}{c}83 \\
(71) \\
81 \\
(70) \\
n(65)\end{array}$ & $\begin{array}{l}80.3 \pm 18.2 \\
83.4 \pm 20.4 \\
80.6 \pm 17.1\end{array}$ & $\begin{array}{l}41.2 \pm 11.1 \\
44.5 \pm 11.6 \\
43.4 \pm 12.5\end{array}$ & $\begin{array}{c}6.5 \pm 7.6 \\
8.4 \pm 10.8 \\
7.1 \pm 9.2\end{array}$ & $\begin{array}{l}\text { a b c d e f } \\
\text { at week } \\
16\end{array}$ \\
\hline
\end{tabular}

Measure 1: intravenous secukinumab $(10 \mathrm{mg} / \mathrm{kg}$ ) or matched placebo at weeks 0 , 2 , and 4 , followed by subcutaneous secukinumab (150 mg or $75 \mathrm{mg})$ or matched placebo every 4 weeks starting at week 8 . Measure 2: subcutaneous secukinumab ( $150 \mathrm{mg}$ or $75 \mathrm{mg}$ ) or matched placebo at baseline; at weeks 1,2 , and 3; and every 4 weeks starting at week 4 . Measure 3: intravenous secukinumab $(10 \mathrm{mg} / \mathrm{kg})$ or matched placebo at weeks 0 , 2, and 4 , followed by subcutaneous secukinumab (300 mg or $150 \mathrm{mg}$ ) or matched placebo every 4 weeks starting at week 4 . Measure 4:subcutaneous secukinumab (150 mg) with loading dose $(150 \mathrm{mg})$, without loading dose or placebo at weeks 1, 2, and 3 and every 4 weeks starting at week 4 . (a) ASAS20 response, (b) ASAS 40 response, (c) ASAS5/6 response, (d) SF-36 PCS score (change from baseline), (e) ASQoL score (change from baseline).

Studies were included if at least one outcome was reported. Only studies that were designed as randomized controlled trials were included. Articles of other publication types were excluded.

2.3. Study Selection and Data Extraction. Two authors screened all the titles and abstracts independently to identify the studies that met the inclusion criteria. Then, the full texts of all the potentially relevant articles were reviewed to assess their eligibility. When multiple articles describing the same trial were published, the most complete article was included, and disagreements were settled through discussion.

Two authors extracted data using a standard form, and a third reviewer verified its accuracy. The following data were extracted from the eligible articles: first author and publication year, study design, characteristics of patients (sex, weight, age, and duration of AS), intervention, and outcomes. Data reported in other formats (mean $\pm \mathrm{SE}$ ) were transformed into the mean \pm SD format in accordance with the Cochrane Handbook recommendations.

2.4. Quality Assessment. Two authors independently evaluated the methodological quality of the included studies in accordance with the Cochrane quality assessment tool based on seven items: random sequence generation, allocation

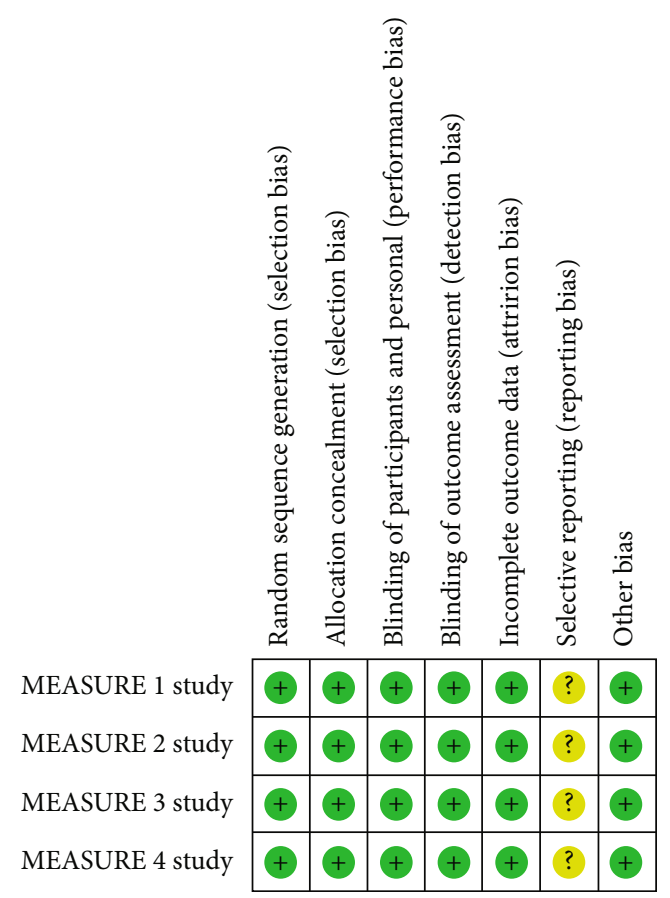

FIGURE 2: Risk of bias graph: review authors' judgement about each risk of bias item for each included study. 
TABLE 2: The GRADE evidence quality for each outcome.

\begin{tabular}{|c|c|c|c|c|c|c|}
\hline Outcomes & No. of included trials & No. of & atients & MD or RR $(95 \% \mathrm{CI})$ & Heterogeneity & GRADE \\
\hline SEC150mg VS PLB & & SEC150mg & PLB & & & \\
\hline ASAS20 response & 4 & 388 & 389 & $1.71(1.32,2.22)$ & $I^{2}=62 \%, P=0.05$ & Moderate \\
\hline ASAS40 response & 4 & 388 & 389 & $2.16(1.33,3.53)$ & $I^{2}=72 \%, P=0.01$ & Moderate \\
\hline ASAS5/6 response & 4 & 388 & 389 & $2.87(1.58,5.24)$ & $I^{2}=80 \%, P=0.002$ & Low \\
\hline SF-36 PCS & 3 & 314 & 313 & $3.80(2.52,5.08)$ & $I^{2}=26 \%, P=0.26$ & High \\
\hline ASQOL & 3 & 314 & 313 & $-2.22(-2.95,-1.49)$ & $I^{2}=0 \%, P=0.46$ & High \\
\hline $\mathrm{AE}$ & 4 & 388 & 388 & $1.07(0.93,1.24)$ & $I^{2}=24 \%, P=0.27$ & High \\
\hline SEC75mg VS PLB & & SEC75mg & PLB & & & \\
\hline ASAS20 response & 2 & 197 & 196 & $1.80(1.28,2.55)$ & $I^{2}=39 \%, P=0.20$ & Moderate \\
\hline ASAS40 response & 2 & 197 & 196 & $2.48(1.62,3.82)$ & $I^{2}=0 \%, P=0.92$ & Moderate \\
\hline ASAS5/6 response & 2 & 197 & 196 & $3.63(2.37,5.56)$ & $I^{2}=0 \%, P=0.68$ & Low \\
\hline SF-36 PCS & 2 & 197 & 196 & $3.91(2.14,5.68)$ & $I^{2}=40 \%, P=0.20$ & Moderate \\
\hline ASQOL & 2 & 197 & 196 & $-2.33(-3.26,-1.40)$ & $I^{2}=0 \%, P=0.53$ & Moderate \\
\hline $\mathrm{AE}$ & 2 & 197 & 196 & $1.06(0.80,1.39)$ & $I^{2}=64 \%, P=0.09$ & Low \\
\hline SEC75mg VS SEC150mg & & SEC75mg & SEC150mg & & & \\
\hline ASAS20 response & 2 & 197 & 197 & $0.67(0.32,1.42)$ & $I^{2}=69 \%, P=0.07$ & Low \\
\hline ASAS40 response & 2 & 197 & 197 & $0.77(0.59,1.01)$ & $I^{2}=0 \%, P=0.75$ & Moderate \\
\hline ASAS5/6 response & 2 & 197 & 197 & $0.89(0.71,1.11)$ & $I^{2}=0 \%, P=0.54$ & Moderate \\
\hline SF-36 PCS & 2 & 197 & 197 & $-0.42(-1.74,0.89)$ & $I^{2}=0 \%, P=0.33$ & Low \\
\hline ASQOL & 2 & 197 & 197 & $0.24(-0.68,1.15)$ & $I^{2}=0 \%, P=0.47$ & Moderate \\
\hline $\mathrm{AE}$ & 2 & 197 & 197 & $0.94(0.81,1.08)$ & $I^{2}=0 \%, P=0.58$ & Moderate \\
\hline
\end{tabular}

concealment, blinding of the participants and personnel, blinding of the outcome assessment, incomplete outcome data, selection reporting, and other bias. The studies were considered to have a "low risk of bias", an "unclear risk of bias", or a "high risk of bias" based on the evaluation criteria, and disagreements were settled by a third author.

The quality of evidence was assessed by two authors independently in accordance with the Grading of Recommendations Assessment, Development, and Evaluation (GRADE) criteria [27] based on five items: risk of bias, inconsistency, indirectness, imprecision, and publication bias. The level of evidence was graded based on four grades: "high quality", "moderate quality", "low quality", or "very low quality". High quality indicated that additional research is very unlikely to change our confidence in the estimate of the effect, moderate quality indicated that additional research is likely to have an important impact on our confidence in the estimate of the effect and may change the estimate, low quality indicated that additional research is very likely to have an important impact on our confidence in the estimate of the effect and is likely to change the estimate, and very low quality indicated that we are very uncertain about the estimate.

2.5. Statistical Analysis. All statistical analyses were performed using Review Manager (RevMan 5.3, Cochrane Collaboration, Copenhagen, Denmark). Dichotomous data were expressed as risk ratios (RRs) with 95\% CIs, and contin- uous data were expressed as mean differences (MDs) with 95\% CIs. The heterogeneity of the included studies was evaluated by the $I^{2}$ index. Random-effects models were used in all of the meta-analyses. Statistical significance was defined as $P<0.05$. Subgroup analysis was conducted based on whether the patients previously underwent TNFi treatment. Sensitivity analysis was conducted by removing one single study at a time to explore the impact of an individual study.

\section{Results}

3.1. Study Selection. The steps of study selection were summarized in Figure 1. After the initial search, a total of 1247 articles were identified, 613 of which were ruled out due to duplication. A total of 616 studies were excluded after the titles and abstracts were read. Then, the full texts of the remaining 18 articles were retrieved for further assessment, and 13 articles were eliminated for the following reasons: the study was not an RCT, there was no placebo group, the study did not meet the inclusion criteria for outcomes, or it was a duplicate of a previous publication. Among the 5 studies [18-22] that met our inclusion criteria, one [18] was excluded because it used a different method of administration of secukinumab. Ultimately, 4 RCTs were included in the quantitative analysis [19-22].

3.2. Characteristics of the Included Studies. The characteristics of the included trials and patients were shown in 


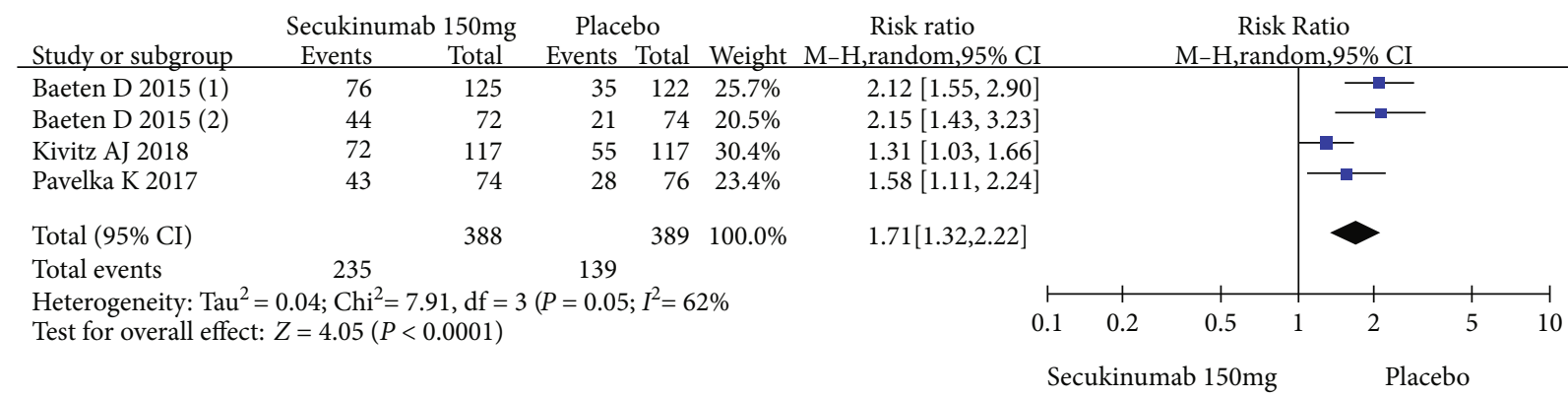

(a)

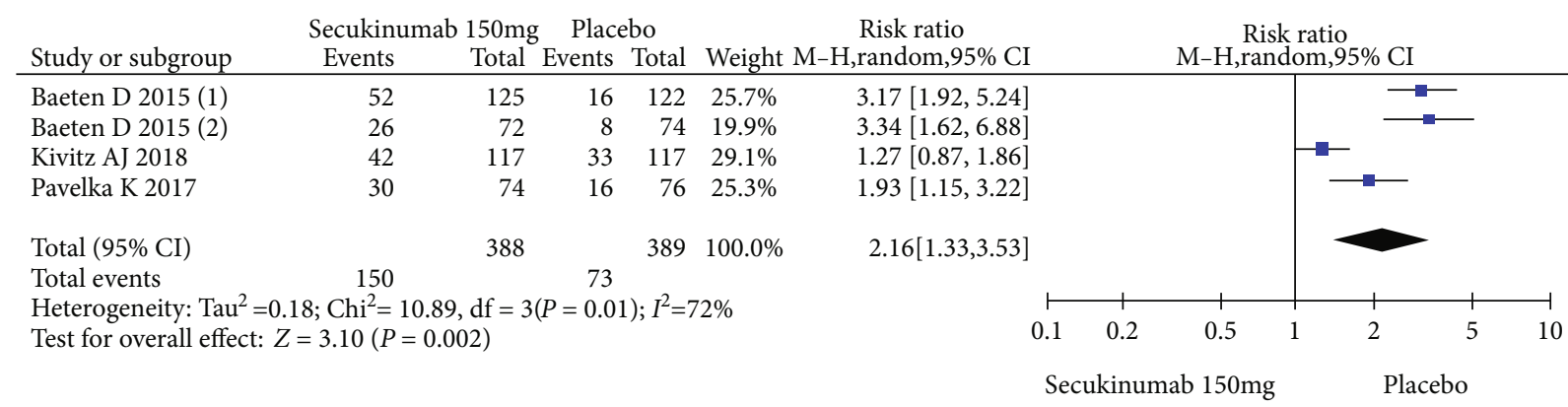

(b)

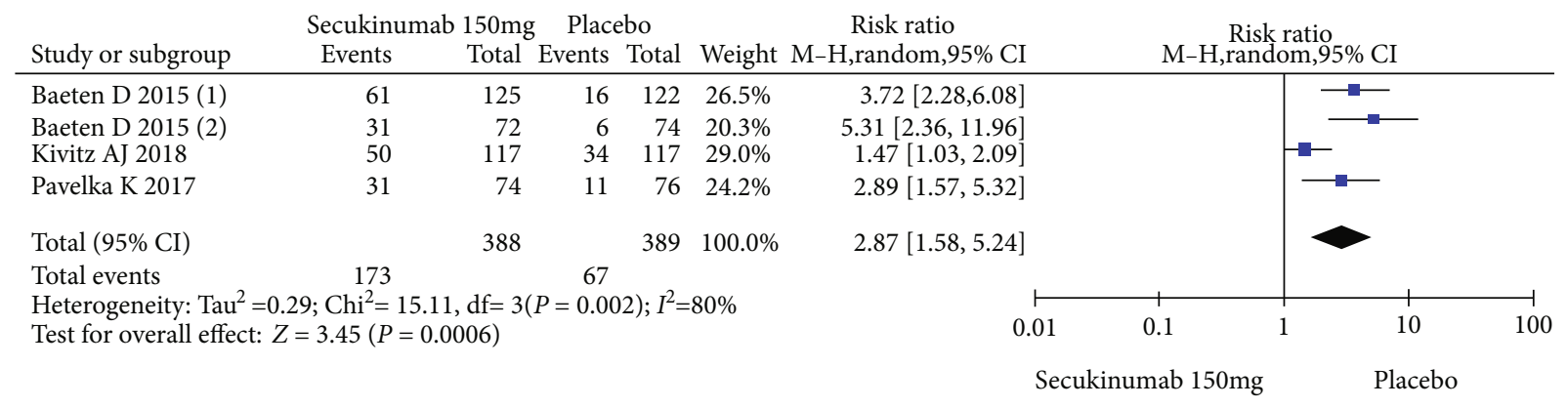

(c)

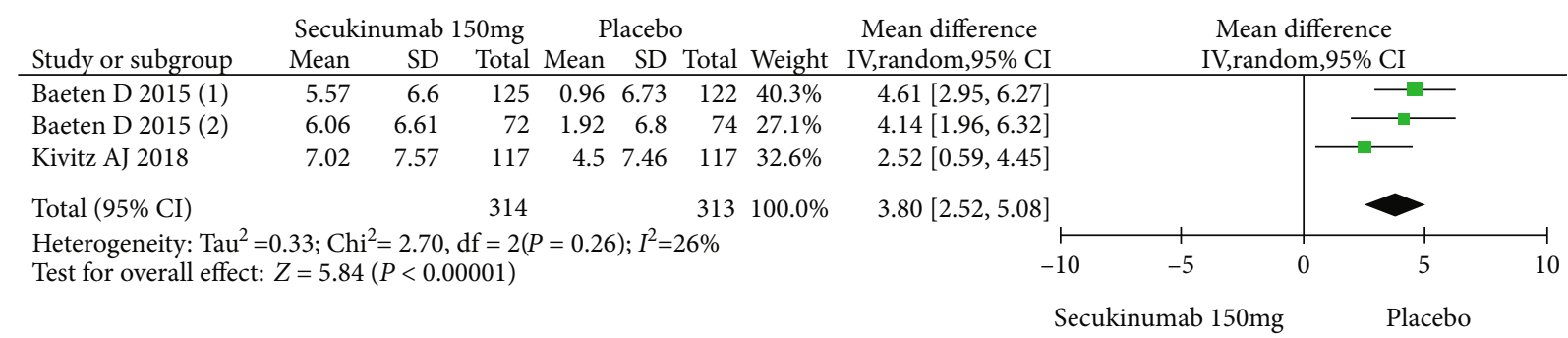

(d)

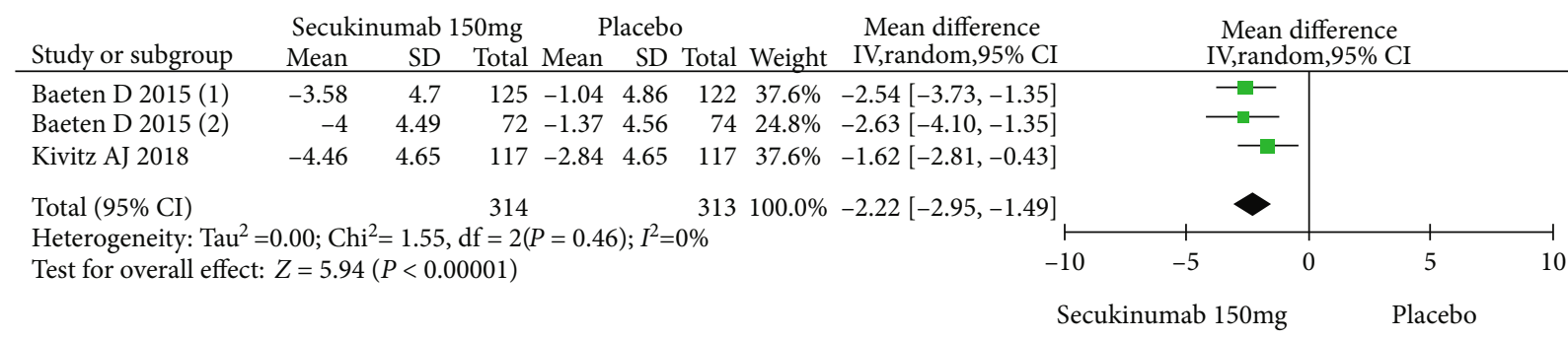

(e)

Figure 3: Continued. 


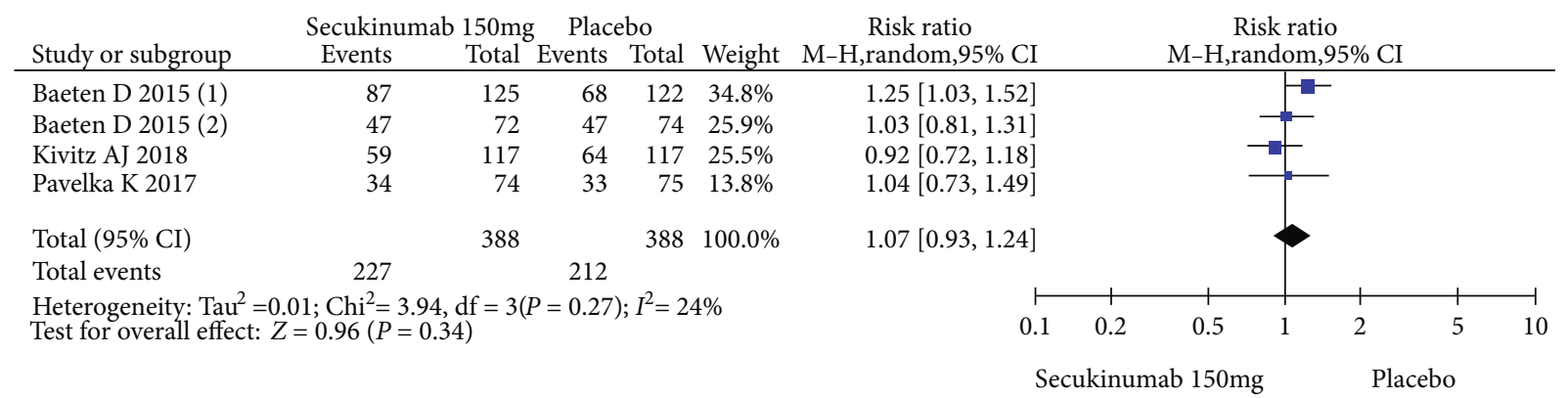

(f)

Figure 3: Meta-analysis of secukinumab $150 \mathrm{mg}$ versus placebo at week 16. (a) ASAS 20 response, (b) ASAS 40 response, (c) ASAS 5/6 response, (d) SF-36 PCS score (change from baseline), (e) ASQoL score (change from baseline), (f) AEs. Baeten 2015 (1): MEASURE 1 study, Baeten 2015 (2): MEASURE 2 study.

Table 1. All of the studies were randomized, double-blind, placebo-controlled, multicenter phase 3 trials. The patients with active AS met the modified New York criteria and were over 18 years old. The other inclusion criteria included a score of at least 4 points on the bath ankylosing spondylitis disease activity index (BASDAI) and a score of at least $4 \mathrm{~cm}$ on a $10 \mathrm{~cm}$ visual analogue scale (VAS) for spinal pain, regardless of whether the patients were being treated with the maximum tolerated doses of NSAIDs. A history of treatment with disease-modifying and antirheumatic drugs (DMARDs) was permitted. The patients could continue to receive sulfasalazine, methotrexate, prednisone or the equivalent, and NSAIDs with a stable dose. In all trials, the patients were randomized into a placebo group or one of two secukinumab groups, and the baseline characteristics of these groups were comparable.

3.3. Results of the Quality Assessment. The risk of bias assessment results for the included trials was shown in Figure 2. All trials performed blinding of the AS patients and research investigators. Randomization and concealment of allocation were conducted with effective approaches. There was a low risk of incomplete outcome data and other bias, while the risk of reporting bias was unclear in the 4 RCTs. The quality assessment results for the outcomes were summarized in Table 2.

\section{Results of the Meta-Analysis}

4.1. Secukinumab $150 \mathrm{mg}$ versus a Placebo. Four RCTs with 777 patients in the secukinumab $150 \mathrm{mg}$ arm and placebo arm reported the ASAS20, ASAS40, and ASAS5/6 response rates at week 16, and the estimated RRs were 1.71 (95\% CI $=1.32$ to $2.22, P<0.0001), 2.16(95 \% \mathrm{CI}=1.33$ to $3.53, P$ $=0.002)$, and $2.87(95 \% \mathrm{CI}=1.58$ to $5.24, P=0.0006)$, respectively (Figure 3). Three trials involving 627 patients published the scores of the SF-36 PCS and ASQoL (mean change from baseline) in the secukinumab $150 \mathrm{mg}$ group and the placebo group, and the estimated MDs were 3.80 $(95 \% \mathrm{CI}=2.52$ to $5.08, P<0.00001)$ and $-2.22(95 \% \mathrm{CI}=-$ 2.95 to $-1.49, P<0.00001$ ), respectively (Figure 3 ). There were significant differences in the above indicators between the two groups. The number of AEs at 16 weeks was considered the safety outcome in our meta-analysis. The results of 776 patients from four RCTs were pooled. The estimated $\mathrm{RR}$ was 1.07 (95\% CI $=0.93$ to $1.24, P=0.34$ ) (Figure 3 ), showing no significant difference between the two groups. It should be noted that the two experimental arms of NCT02159053 were both secukinumab $150 \mathrm{mg}$. Therefore, the results from one group (secukinumab $150 \mathrm{mg}$ with no load) with a lower level of heterogeneity were included in our meta-analysis.

4.2. Secukinumab $75 \mathrm{mg}$ versus a Placebo. Two RCTs including 393 patients assessed the efficacy and safety of secukinumab $75 \mathrm{mg}$ and a placebo at week 16. Secukinumab $75 \mathrm{mg}$ showed higher response rates on ASAS20, ASAS40, and ASAS5/6, with estimated RRs of 1.80 (95\% CI $=1.28$ to 2.55, $P=0.0009$ ), 2.48 (95\% CI $=1.62$ to $3.82, P<0.0001$ ), and 3.63 (95\% CI $=2.37$ to $5.56, P<0.00001)$, respectively (Figure 4). For the SF-36 PCS and ASQoL scores (mean change from baseline), the estimated MDs were 3.91 (95\% $\mathrm{CI}=2.14$ to $5.68, P<0.0001)$ and $-2.33(95 \% \mathrm{CI}=-3.26$ to $-1.40, P<0.00001$ ), respectively (Figure 4 ). The metaanalysis revealed significant differences in these indexes between the two groups. In addition, no significant difference was found between the secukinumab $75 \mathrm{mg}$ group and the placebo group in terms of AEs, with an RR of 1.06 (95\% CI $=0.80$ to $1.39, P=0.69$ ) (Figure 4 ).

4.3. Secukinumab $75 \mathrm{mg}$ versus Secukinumab $150 \mathrm{mg}$. The data from 394 patients from two trials were pooled to compare the efficacy and safety of secukinumab $75 \mathrm{mg}$ versus $150 \mathrm{mg}$ for AS. The estimated RRs of the ASAS20, ASAS40, and ASAS5/6 were $0.67(95 \% \mathrm{CI}=0.32$ to $1.42, P=0.30)$, $0.77(95 \% \mathrm{CI}=0.59$ to $1.01, P=0.06)$, and $0.89(95 \% \mathrm{CI}=$ 0.71 to $1.11, P=0.29$ ), respectively (Figure 5 ). The estimated MDs of the SF-36 PCS and ASQoL scores (mean change from baseline) were $-0.42(95 \% \mathrm{CI}=-1.74$ to $0.89, P=0.53$ ) and $0.24(95 \% \mathrm{CI}=-0.68$ to $1.15, P=0.61)$, respectively (Figure 5). The pooled results revealed no significant difference in these outcomes between the two groups. In terms of AEs, the estimated $\mathrm{RR}$ was $0.94(95 \% \mathrm{CI}=0.81$ to $1.08, P=$ 


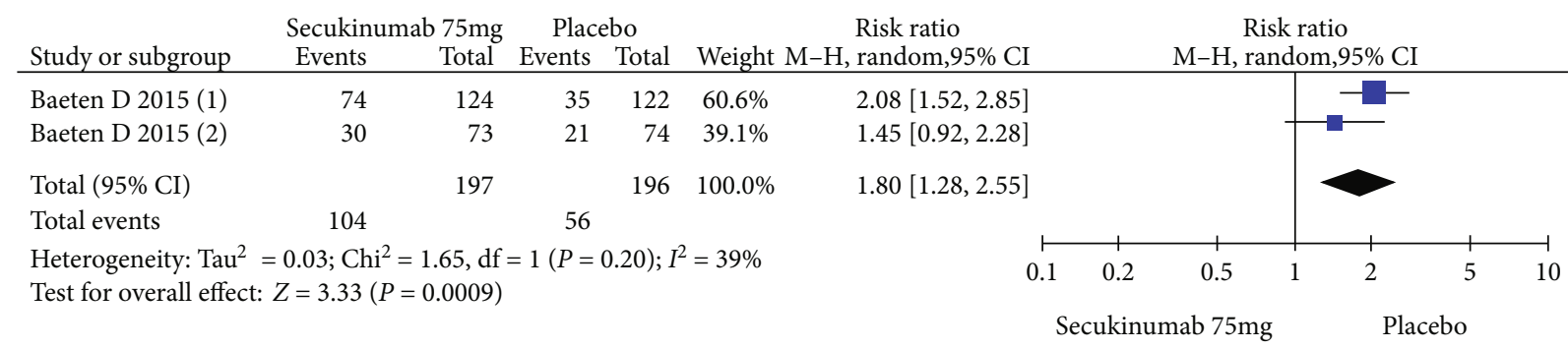

(a)

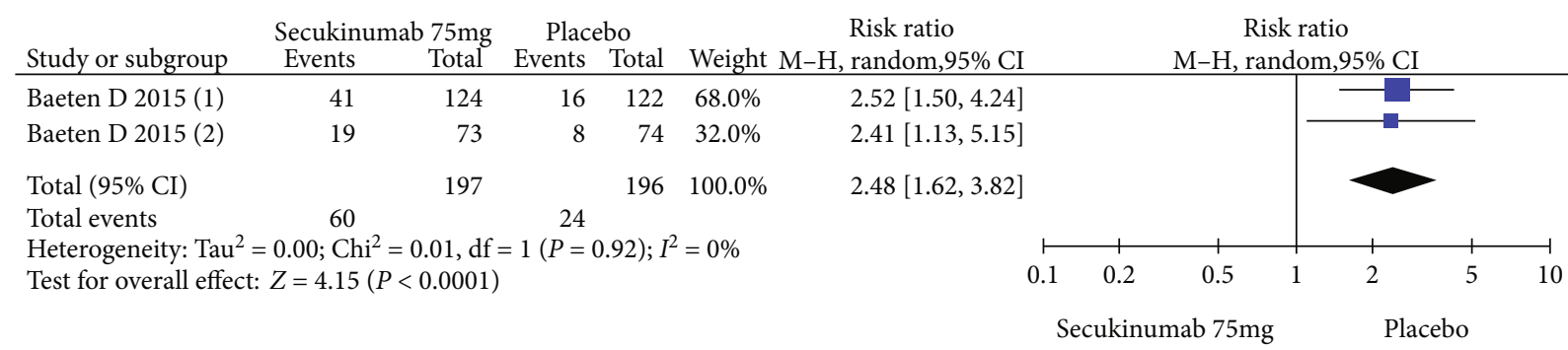

(b)

\begin{tabular}{|c|c|c|c|c|c|}
\hline \multirow[b]{2}{*}{ Study or subgroup } & \multicolumn{2}{|c|}{ Secukinumab $75 \mathrm{mg}$} & \multicolumn{2}{|c|}{ Placebo } & \multirow[b]{2}{*}{ Weigh } \\
\hline & Events & Total & Events & Total & \\
\hline Baet & 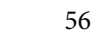 & 124 & 16 & 122 & 3.7 \\
\hline Baete & 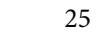 & & 6 & 74 & 26.3 \\
\hline Total & & 197 & & 196 & 100. \\
\hline $\begin{array}{l}\text { Total events } \\
\text { Heterogeneity: T }\end{array}$ & $\begin{array}{c}81 \\
0 \cdot \mathrm{Ch}\end{array}$ & 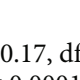 & $\begin{array}{r}22 \\
1(P=\end{array}$ & 0.68 & $=0$ \\
\hline
\end{tabular}

(c)
Risk ratio Risk ratio $\mathrm{M}-\mathrm{H}$, random, $95 \% \mathrm{CI}$

$3.44[2.10,5.66$

$4.22[1.84,9.69]$

$3.63[2.37,5.56]$

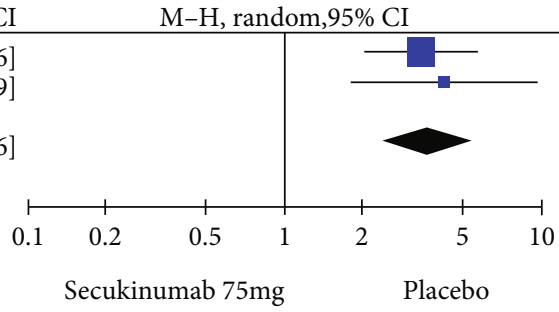

Secukinumab $75 \mathrm{mg}$

Mean difference IV, random, 95\% CI

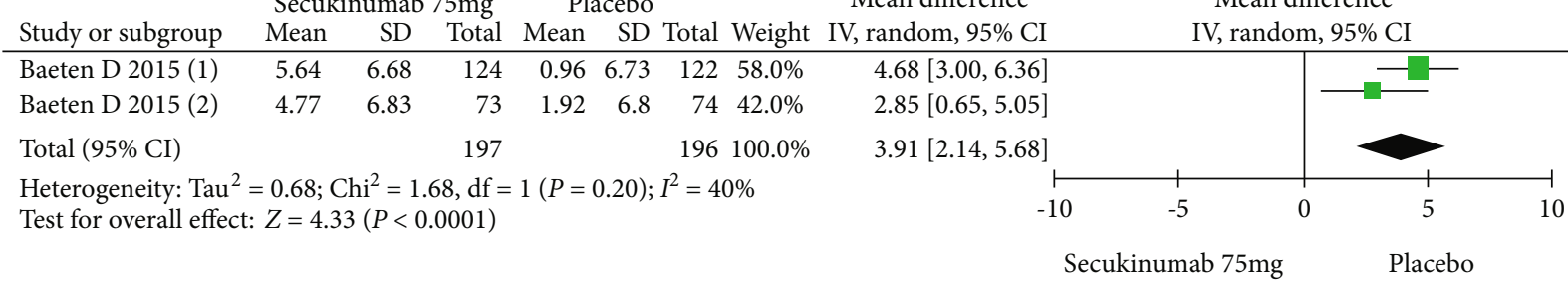

(d)

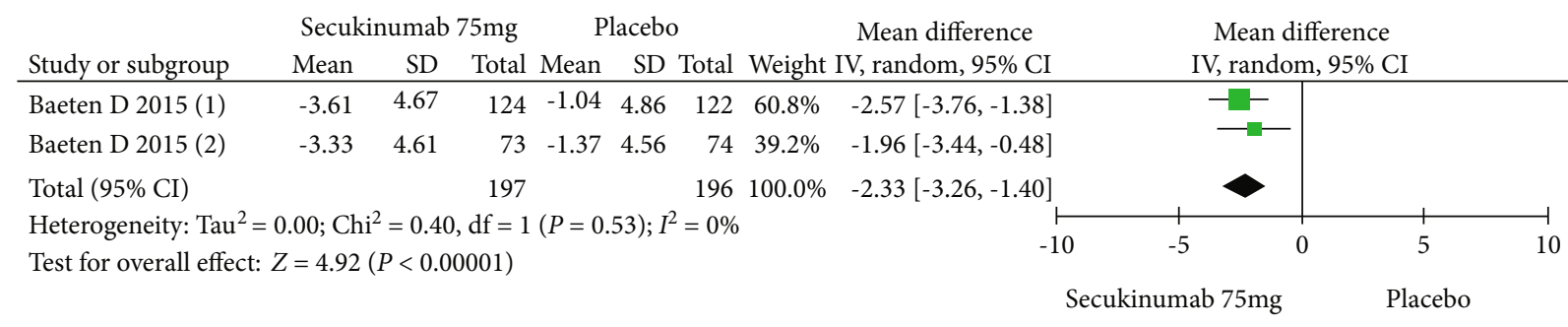

(e)

FIgURE 4: Continued. 


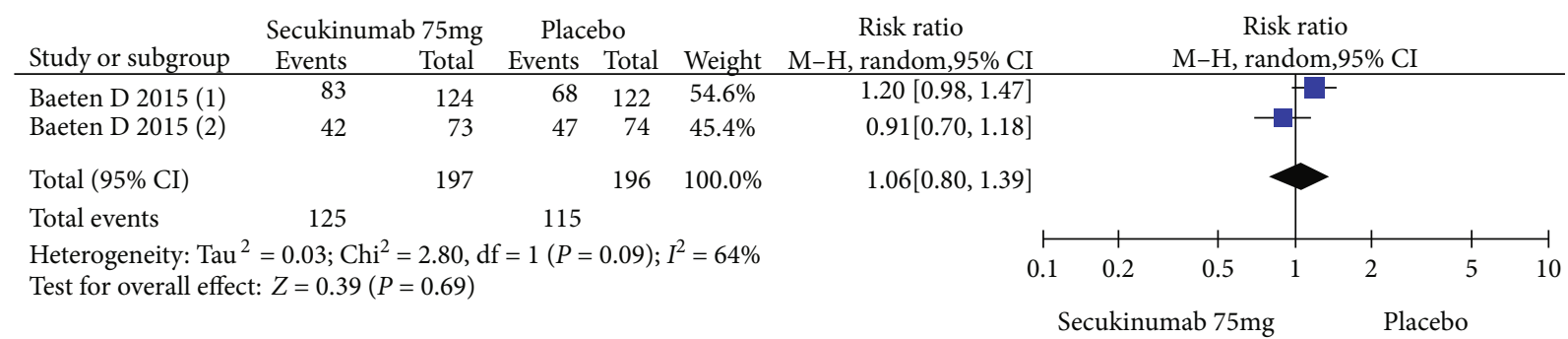

(f)

Figure 4: Meta-analysis of secukinumab $75 \mathrm{mg}$ versus placebo at week 16. (a) ASAS 20 response, (b) ASAS 40 response, (c) ASAS 5/6 response, (d) SF-36 PCS score (change from baseline), (e) ASQoL score (change from baseline), (f) AEs. Baeten 2015 (1): MEASURE 1 study, Baeten 2015 (2): MEASURE 2 study.

0.37) (Figure 5), showing no significant difference between the two groups.

4.4. Subgroup Analysis. To comprehensively evaluate the efficacy of secukinumab $150 \mathrm{mg}$, subgroup analysis was conducted based on whether the patients previously underwent TNFi treatment. Among the TNFi-naive group, the RRs of the ASAS20, ASAS40, and ASAS5/6 were 1.57 (95\% CI = 1.16 to $2.13, P=0.004), 1.65$ (95\% CI $=1.16$ to $2.36, P=$ $0.005)$, and 2.21 (95\% $\mathrm{CI}=1.32$ to $3.70, P=0.003)$, respectively, and the differences were statistically significant (Figure 6). In the TNF-IR group, the RRs of the ASAS20, ASAS40, and ASAS5/6 were $1.44(95 \% \mathrm{CI}=1.04$ to $1.99, P$ $=0.03), 2.22(95 \% \mathrm{CI}=0.66$ to $7.41, P=0.20)$, and 4.86 (95\% CI $=0.53$ to $44.93, P=0.16$ ), respectively, and the magnitudes of improvements in the ASAS40 and ASAS5/6 were statistically nonsignificant (Figure 6).

4.5. Sensitivity Analysis. In the meta-analysis of secukinumab $150 \mathrm{mg}$ versus a placebo, the heterogeneity of all outcomes ranged from 0 to $80 \%$. We conducted a sensitivity analysis by removing one single trial each time, and the results suggested that the heterogeneity was mainly attributed to a single study, the study by Kivitz et al. [21].

\section{Discussion}

To our knowledge, this was the first meta-analysis that assessed the short-term efficacy and safety of secukinumab in the management of AS. The present study consisted of three comparisons. In general, improvements in the clinical response and patient-reported outcomes were observed with the secukinumab $150 \mathrm{mg}$ and $75 \mathrm{mg}$ regimens at week 16, and there was no increased risk of AEs. Moreover, the superiority of secukinumab $150 \mathrm{mg}$ over secukinumab $75 \mathrm{mg}$ seemed to be limited, since no significant difference was detected in any endpoint between the two groups.

Four phase 3 studies (MEASURE 1-4) were included in the meta-analysis of secukinumab $150 \mathrm{mg}$ versus a placebo [19-22]. The results showed that the secukinumab $150 \mathrm{mg}$ yielded greater improvements in the clinical response and patient-reported outcomes for AS patients than did a placebo at week 16. The results of most included trials were consistent with those of our meta-analysis, except those of a single study
(MEASURE 4) [21], which contributed to significant heterogeneity. After 16 weeks of treatment, in the MEASURE 4 study, the superiority of secukinumab $150 \mathrm{mg}$ over a placebo was inconspicuous, because the patients in the placebo group exhibited greater improvements in efficacy outcomes than did those in other studies. The possible reason for such a higher-than-expected response rate was that under the influence of previous studies, both the patients and investigators might have become increasingly aware of the established efficacy of secukinumab and tended to report better outcomes [21]. In addition, we conducted a subgroup analysis based on whether AS patients previously underwent TNFi treatment. At week 16, secukinumab $150 \mathrm{mg}$ was associated with a significantly higher ASAS20 response rate, regardless of whether the AS patients previously underwent TNFi treatment. In the TNF-IR group, there was a trend that secukinumab $150 \mathrm{mg}$ provided higher ASAS40 and ASAS5/6 response rates, although the magnitudes of the improvements were statistically nonsignificant. These results suggested that secukinumab $150 \mathrm{mg}$ provided benefits for TNFi-naive and TNFIR patients.

The efficacy of the secukinumab $75 \mathrm{mg}$ regimen for the management of AS was controversial. The results from the MEASURE 1 study showed that secukinumab $75 \mathrm{mg}$ was associated with notable improvements in the clinical response and patient-reported outcomes at week 16 [19]. However, this superiority of the secukinumab $75 \mathrm{mg}$ regimen over a placebo was not observed in the MEASURE 2 study. Because the improvements in all the efficacy outcomes were statistically nonsignificant [19]. These conflicting results might originate from the different methods of administration of secukinumab between the two studies. Obviously, the secukinumab $75 \mathrm{mg}$ group in the MEASURE 1 study received a higher loading dose based on their body weight in the first 4 weeks [19]. This interpretation was supported by our metaanalysis results of secukinumab $75 \mathrm{mg}$ versus $150 \mathrm{mg}$, which revealed a trend of better efficacy with a higher dose, although no significant difference was detected between the two groups. In addition, secukinumab $300 \mathrm{mg}$ was shown to be more effective than $150 \mathrm{mg}$ for PsA patients [28], suggesting that there might be a dose-dependent effect.

Inflammation and excessive bone formation are two notable characteristics of AS. Although the precise molecular mechanism remains to be fully illustrated, cumulative 


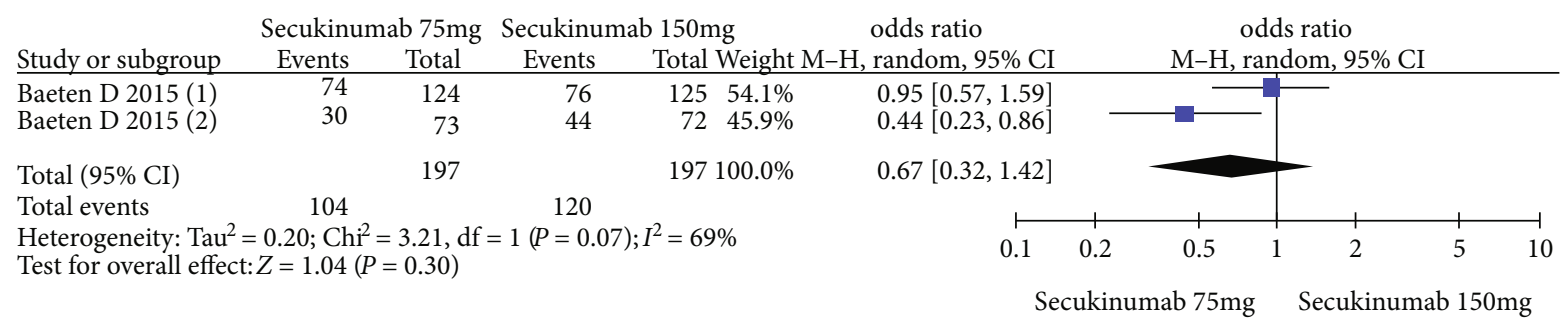

(a)

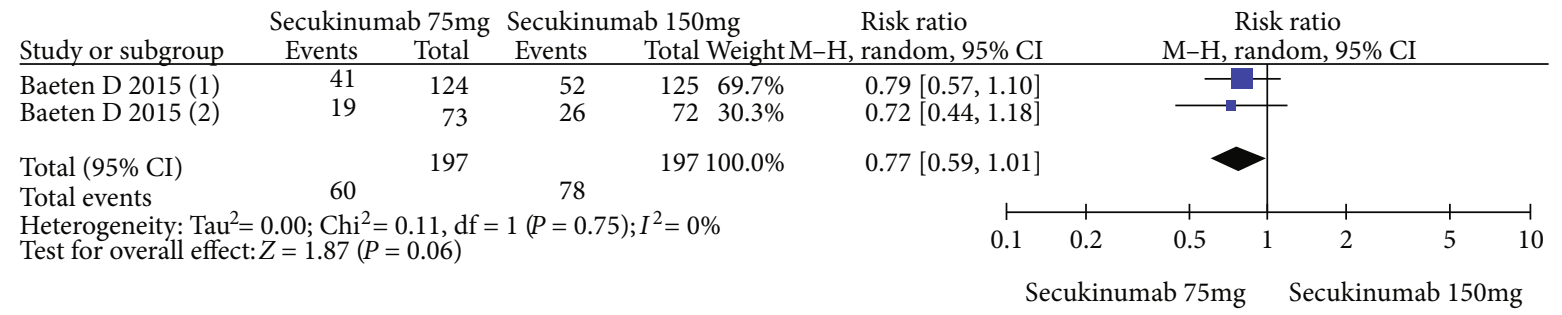

(b)

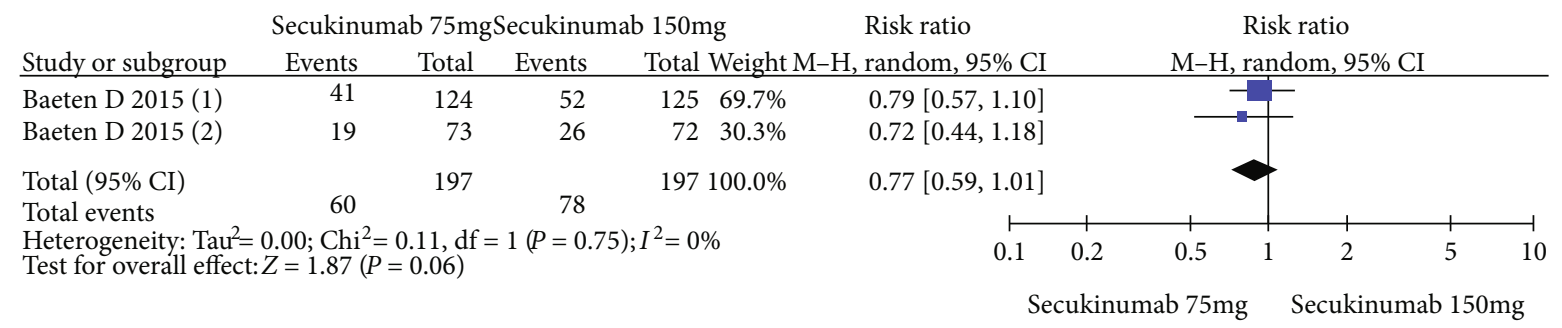

(c)

Secukinumab $75 \mathrm{mg}$ Secukinumab $150 \mathrm{mg}$

Mean difference \begin{tabular}{llllll} 
Study or subgroup & Mean & SD & Total & Mean & SD \\
\hline
\end{tabular}

\begin{tabular}{|c|c|c|c|c|c|c|}
\hline $\begin{array}{l}\text { Baeten D } 2015 \text { (1) } \\
\text { Baeten D } 2015(2)\end{array}$ & $\begin{array}{l}5.64 \\
4.77\end{array}$ & $\begin{array}{l}6.68 \\
6.83\end{array}$ & $\begin{array}{r}124 \\
73\end{array}$ & $\begin{array}{l}5.57 \\
6.06\end{array}$ & $\begin{array}{r}6.6 \\
6.61\end{array}$ & $\begin{array}{rl}125 & 63.8 \% \\
72 & 36.2 \%\end{array}$ \\
\hline Total $(95 \%$ CI $)$ & & & 197 & & & $197100.0 \%$ \\
\hline
\end{tabular}

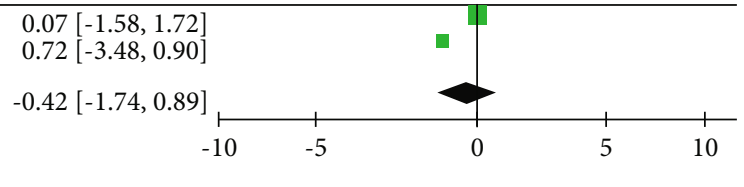

(d)

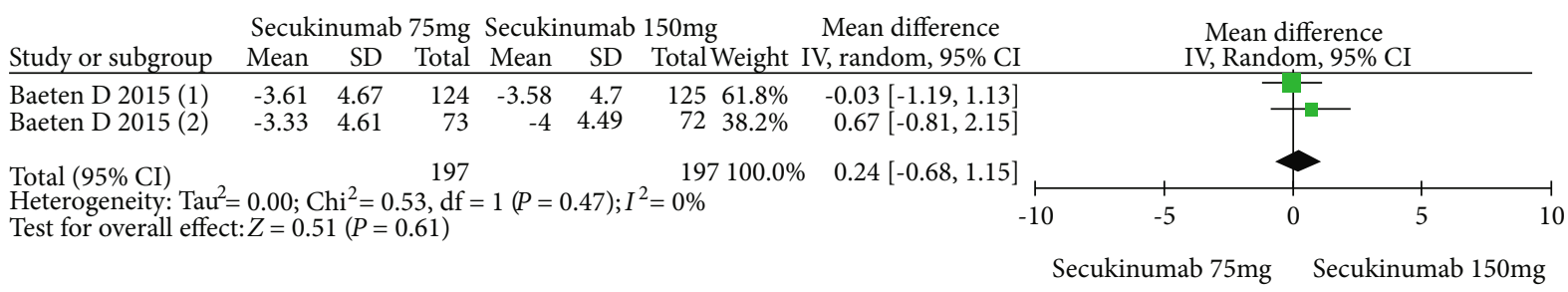

(e)

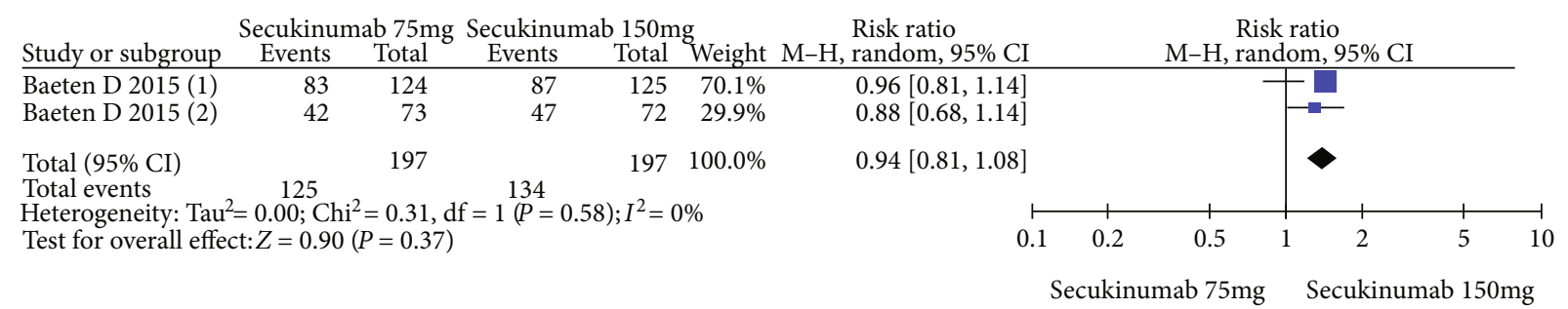

(f)

Figure 5: Meta-analysis of secukinumab $75 \mathrm{mg}$ versus $150 \mathrm{mg}$ at week 16. (a) ASAS 20 response, (b) ASAS 40 response, (c) ASAS 5/6 response, (d) SF-36 PCS score (change from baseline), (e) ASQoL score (change from baseline), (f) AEs. Baeten 2015 (1): MEASURE 1 study, Baeten 2015 (2): MEASURE 2 study. 


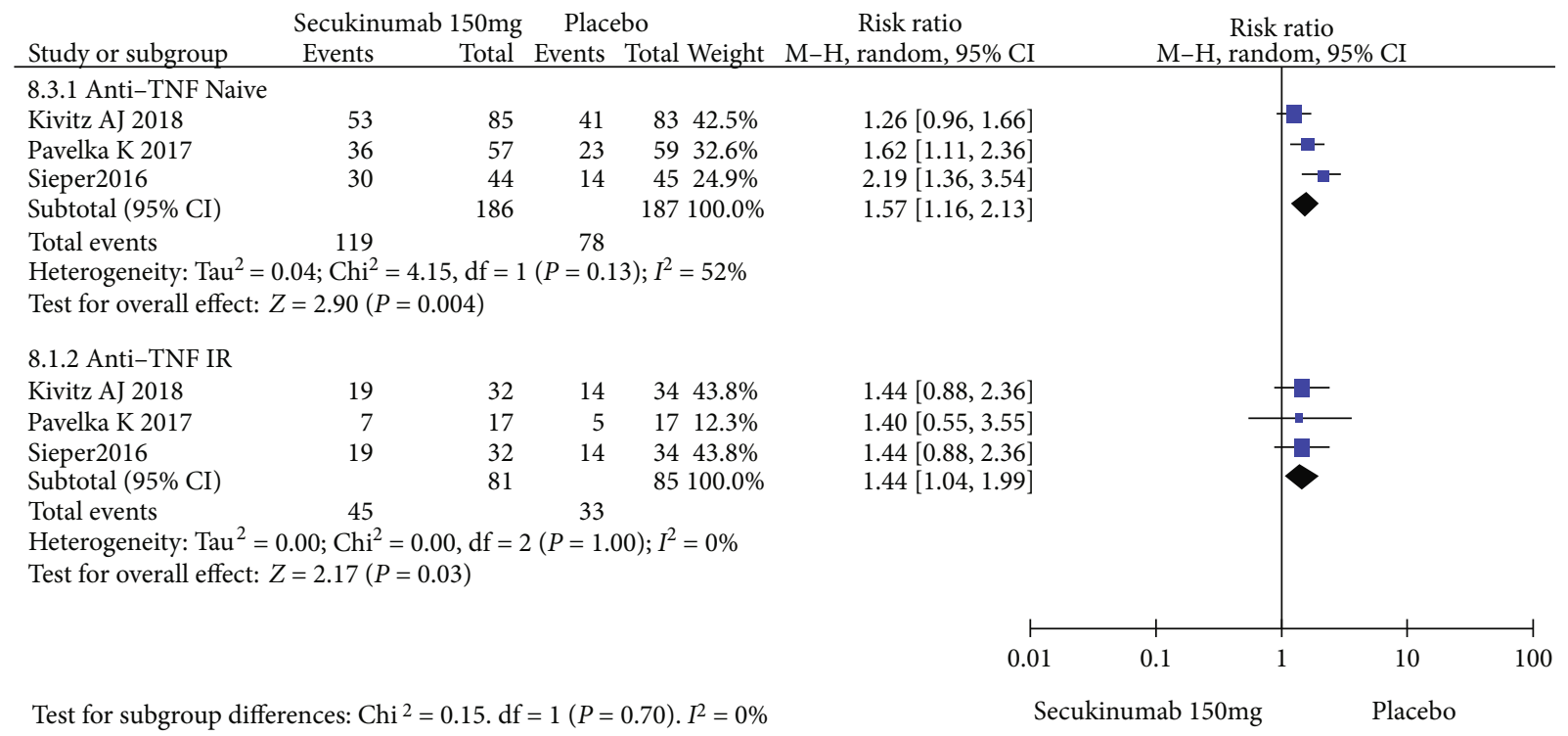

(a)

\begin{tabular}{lrrrrr} 
& \multicolumn{2}{c}{$\begin{array}{c}\text { Secukinumab 150mg } \\
\text { Events }\end{array}$} & Total & Placebo \\
Events & Total & Weight \\
\hline 8.2.1 Anti-TNF Naive & & & & & \\
Kivitz AJ 2018 & 33 & 85 & 25 & 83 & $46.6 \%$ \\
Pavelka K 2017 & 25 & 57 & 14 & 59 & $32.5 \%$ \\
Sieper2016 & 19 & 44 & 8 & 45 & $20.9 \%$ \\
Subtotal (95\% CI) & & 186 & & 187 & $100.0 \%$ \\
Total events & 77 & & 47 & \\
Heterogeneity: Tau & $2=0.02 \cdot$ Chi $^{2}=2.60, \mathrm{df}=2(P=0.27) ; I^{2}=23 \%$
\end{tabular}

Heterogeneity: $\mathrm{Tau}^{2}=0.02 \cdot \mathrm{Chi}^{2}=2.60, \mathrm{df}=2(P=0.27) ; I^{2}=23 \%$

Test for overall effect: $Z=2.79(P=0.005)$

\subsubsection{Anti-TNF IR}

Pavelka K 2017

Sieper2016

Subtotal (95\% CI)

Total events

$\begin{array}{lllll}9 & 32 & 8 & 34 & 52.1 \% \\ 5 & 17 & 2 & 17 & 33.4 \% \\ 7 & 28 & 0 & 29 & 14.5 \% \\ & 77 & & 80 & 100.0 \%\end{array}$

$21 \quad 10$

Heterogeneity: $\mathrm{Tau}^{2}=0.55 ; \mathrm{Chi}^{2}=3.87, \mathrm{df}=2(P=0.14) ; I^{2}=48 \%$

Test for overall effect: $Z=1.29(P=0.20)$

Test for subgroup differences: $\mathrm{Chi}^{2} . \mathrm{df}=1(P=0.65) I^{2}=0 \%$

Risk ratio

, random, 95\% CI

Risk ratio
$1.29[0.84,1.97]$

$1.85[1.07,3.18]$

$2.43[1.19,4.96]$

$1.65[1.16,2.36]$ M-H, random, 95\% CI

$$
\begin{array}{r}
1.20[0.53,2.72] \\
2.50[0.56,11.16] \\
15.52[0.93,259.51] \\
2.22[0.66,7.41]
\end{array}
$$

Secukinumab 150mg

Placebo

(b)

FIgure 6: Continued. 


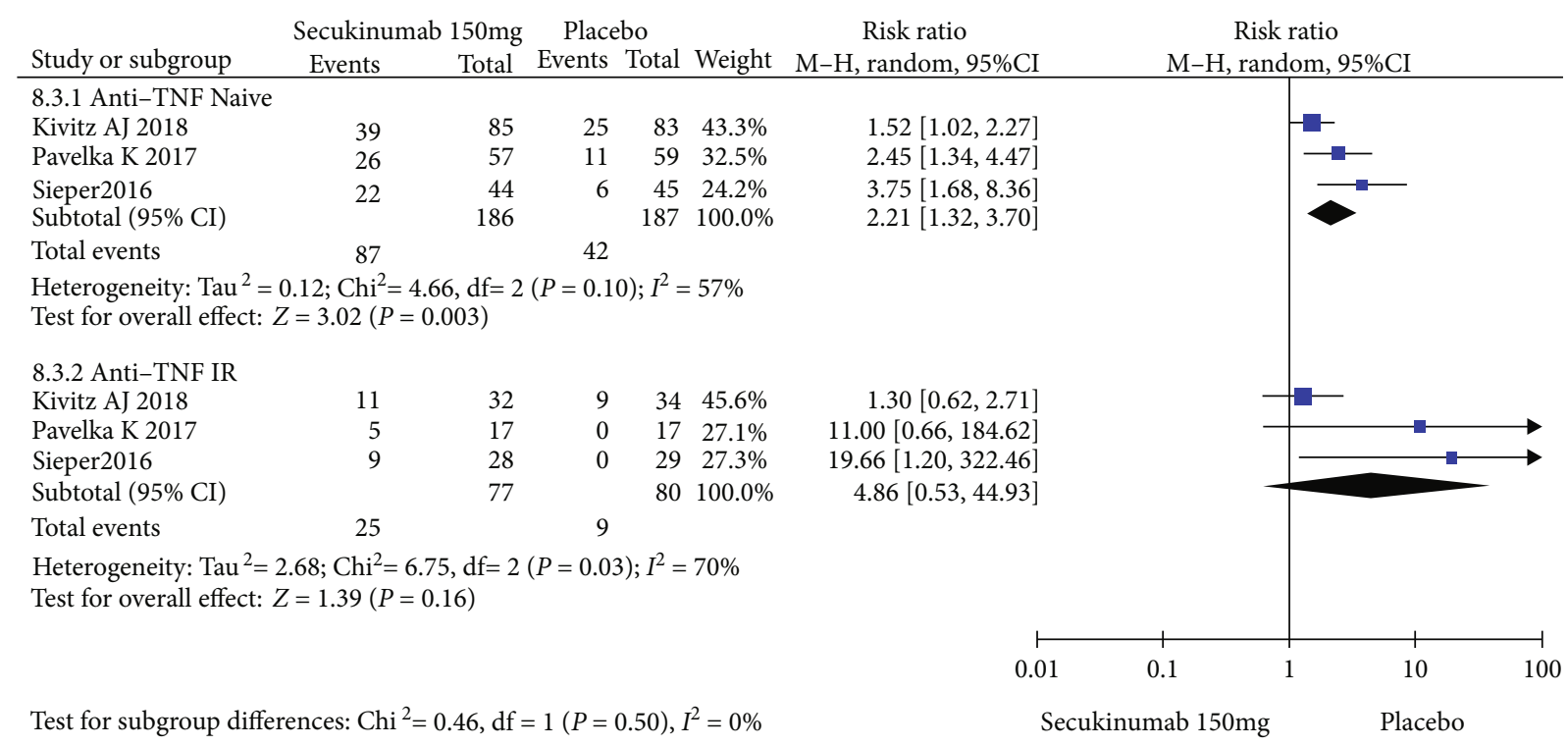

(c)

Figure 6: Subgroup analysis of secukinumab $150 \mathrm{mg}$ versus placebo at week 16. (a) ASAS 20 response, (b) ASAS 40 response, (c) ASAS 5/6 response.

evidence suggests that IL-17 plays a pivotal role in these two processes. IL-17 is a proinflammatory cytokine that can activate the nuclear factor $\kappa \mathrm{B}(\mathrm{NF}-\kappa \mathrm{B})$ pathway and enhance the production of various cytokines such as IL-1B, IL-6, IL-8, and TNF- $\alpha$ [10]. The release of these cytokines initiates and amplifies the cytokine cascade, leading to uncontrolled inflammation. In addition, IL-17 also contributes to the regulation of bone homeostasis. It has been shown that IL-17 not only promotes osteoclastic differentiation and joint destruction by upregulating the receptor $\mathrm{NF}-\kappa \mathrm{B}$ ligand (RANKL) but also facilitates osteoblastogenesis and excessive bone formation $[29,30]$. These processes occur sequentially rather than in parallel, leading to the progression of AS [4]. Consistent with these results, our meta-analysis further confirms that the IL-23/IL-17 axis is involved in the pathogenesis of AS and that IL-17 is an effective target for the management of AS.

It should be noted that our study had some limitations. First, the sample size of this meta-analysis was relatively small since only four RCTs were included for quantitative synthesis. More large-sample and high-quality RCTs are needed to complete our study. Second, the methods of administration of secukinumab differed across the four trials in the first 8 weeks, which might have influenced the outcomes in the short-term setting. Moreover, the placebo recipients of all trials were switched to the secukinumab group after week 16 . To generate meaningful results, our study only focused on the placebo-controlled period. Thus, we were not able to evaluate the long-term efficacy and safety of secukinumab for the management of AS. Finally, our assessment of secukinumab was not comprehensive due to the limited amount of data available. Other outcomes, especially radiographic responses that reflect the progression of AS, should be assessed in future studies.

\section{Conclusions}

Secukinumab is effective in treating AS and generally well tolerated by AS patients in the short term, regardless of whether the patients previously underwent TNFi treatment. The superiority of secukinumab $150 \mathrm{mg}$ over secukinumab $75 \mathrm{mg}$ seems to be limited. However, only four trials were included in the statistical analysis, and more large-sample and high-quality RCTs are needed in the future to further evaluate the efficacy and safety of secukinumab for the management of AS.

\section{Data Availability}

All data generated and analyzed during the study are available from the corresponding author upon request.

\section{Conflicts of Interest}

The authors declare that there is no conflicts of interest.

\section{Authors' Contributions}

Yu Zhou and Jinhui Ma are the joint first author.

\section{Acknowledgments}

This project was supported by the China-Japan Friendship Hospital project (No. 2018-1-QN-9) and Beijing Natural Science Foundation (No. 7204301).

\section{References}

[1] F. Babaie, M. Hasankhani, H. Mohammadi et al., "The role of gut microbiota and IL-23/IL-17 pathway in ankylosing 
spondylitis immunopathogenesis: new insights and updates," Immunology Letters, vol. 196, pp. 52-62, 2018.

[2] J. Zhao, C. Huang, H. Huang et al., "Prevalence of ankylosing spondylitis in a Chinese population: a systematic review and meta-analysis," Rheumatology International, vol. 40, no. 6, pp. 859-872, 2020.

[3] J. Sieper, J. Braun, M. Dougados, and D. Baeten, “Axial spondyloarthritis," Nature Reviews Disease Primers, vol. 1, no. 1, 2015.

[4] H.-W. Tseng, M. E. Pitt, T. T. Glant et al., "Inflammationdriven bone formation in a mouse model of ankylosing spondylitis: sequential not parallel processes," Arthritis Research \& Therapy, vol. 18, no. 1, 2016.

[5] D. Connolly, C. Fitzpatrick, and F. O’Shea, "Disease Activity, Occupational Participation, and Quality of Life for Individuals with and without Severe Fatigue in Ankylosing Spondylitis," Occupational Therapy International, vol. 2019, Article ID 3027280, 10 pages, 2019.

[6] D. Simone, M. H. al Mossawi, and P. Bowness, "Progress in our understanding of the pathogenesis of ankylosing spondylitis," Rheumatology, vol. 57, suppl_6, pp. vi4-vi9, 2018.

[7] P. Bowness, "HLA-B27," Annual Review of Immunology, vol. 33, no. 1, pp. 29-48, 2015.

[8] W. Liu, Y. H. Wu, L. Zhang et al., "Elevated serum levels of IL6 and IL-17 may associate with the development of ankylosing spondylitis," International Journal of Clinical and Experimental Medicine, vol. 8, no. 10, pp. 17362-17376, 2015.

[9] Y. Mei, F. Pan, J. Gao et al., "Increased serum IL-17 and IL-23 in the patient with ankylosing spondylitis," Clinical Rheumatology, vol. 30, no. 2, pp. 269-273, 2011.

[10] J. M. G. Ruiz de Morales, L. Puig, E. Daudén et al., "Critical role of interleukin (IL)-17 in inflammatory and immune disorders: an updated review of the evidence focusing in controversies," Autoimmunity Reviews, vol. 19, no. 1, p. 102429, 2020.

[11] E. M. Gravallese and G. Schett, "Effects of the IL-23-IL-17 pathway on bone in spondyloarthritis," Nature Reviews Rheumatology, vol. 14, no. 11, pp. 631-640, 2018.

[12] K. A. Bush, K. M. Farmer, J. S. Walker, and B. W. Kirkham, "Reduction of joint inflammation and bone erosion in rat adjuvant arthritis by treatment with interleukin-17 receptor IgG1 Fc fusion protein," Arthritis and Rheumatism, vol. 46, no. 3, pp. 802-805, 2002.

[13] E. Lubberts, M. I. Koenders, B. Oppers-Walgreen et al., “Treatment with a neutralizing anti-murine interleukin-17 antibody after the onset of collagen-induced arthritis reduces joint inflammation, cartilage destruction, and bone erosion," Arthritis \& Rheumatism, vol. 50, no. 2, pp. 650-659, 2004.

[14] H. Tahir, "Therapies in ankylosing spondylitis-from clinical trials to clinical practice," Rheumatology, vol. 57, suppl_6, pp. vi23-vi28, 2018.

[15] J. Braun, A. Deodhar, R. D. Inman et al., "Golimumab administered subcutaneously every 4 weeks in ankylosing spondylitis: 104-week results of the GO-RAISE study," Annals of the Rheumatic Diseases, vol. 71, no. 5, pp. 661-667, 2012.

[16] M. Abrouk, J. Gandy, M. Nakamura et al., "Secukinumab in the treatment of psoriasis and psoriatic arthritis: a review of the literature," Skin Therapy Letter, vol. 22, no. 4, pp. 1-6, 2017.

[17] Y. Huang, Y. Fan, Y. Liu, W. Xie, and Z. Zhang, "Efficacy and safety of secukinumab in active rheumatoid arthritis with an inadequate response to tumor necrosis factor inhibitors: a meta-analysis of phase III randomized controlled trials," Clinical Rheumatology, vol. 38, no. 10, pp. 2765-2776, 2019.

[18] D. Baeten, X. Baraliakos, J. Braun et al., “Anti-interleukin-17A monoclonal antibody secukinumab in treatment of ankylosing spondylitis: a randomised, double-blind, placebo-controlled trial," Lancet, vol. 382, no. 9906, pp. 1705-1713, 2013.

[19] D. Baeten, J. Sieper, J. Braun et al., "Secukinumab, an Interleukin-17A Inhibitor, in Ankylosing Spondylitis," New England Journal of Medicine, vol. 373, no. 26, pp. 2534-2548, 2015.

[20] K. Pavelka, A. Kivitz, E. Dokoupilova et al., "Efficacy, safety, and tolerability of secukinumab in patients with active ankylosing spondylitis: a randomized, double-blind phase 3 study, MEASURE 3," Arthritis Research \& Therapy, vol. 19, no. 1, p. 285, 2017.

[21] A. J. Kivitz, U. Wagner, E. Dokoupilova et al., "Efficacy and safety of secukinumab $150 \mathrm{mg}$ with and without loading regimen in ankylosing spondylitis: 104-week results from MEASURE 4 study," Rheumatology and therapy, vol. 5, no. 2, pp. 447-462, 2018.

[22] J. Sieper, A. Deodhar, H. Marzo-Ortega et al., "Secukinumab efficacy in anti-TNF-naive and anti-TNF-experienced subjects with active ankylosing spondylitis: results from the MEASURE 2 Study," Annals of the Rheumatic Diseases, vol. 76, no. 3, pp. 571-592, 2017.

[23] M. Kishimoto, A. Taniguchi, A. Fujishige et al., "Efficacy and safety of secukinumab in Japanese patients with active ankylosing spondylitis: 24-week results from an open-label phase 3 study (MEASURE 2-J)," Modern Rheumatology, vol. 30, no. 1, pp. 132-140, 2020.

[24] T. Williams, A. Wadeley, D. Bond, C. Cavill, M. Freeth, and R. Sengupta, "Real-world experience of secukinumab treatment for ankylosing spondylitis at the Royal National Hospital for Rheumatic Diseases, Bath," Clinical Rheumatology, vol. 39, no. 5, pp. 1501-1504, 2020.

[25] M. Magrey, M. Bozyczko, D. Wolin et al., "A pilot study to assess the feasibility of a web-based survey to examine patient-reported symptoms and satisfaction in patients with ankylosing spondylitis receiving secukinumab," Drugs - real world outcomes, vol. 6, no. 2, pp. 83-91, 2019.

[26] A. Liberati, D. G. Altman, J. Tetzlaff et al., "The PRISMA statement for reporting systematic reviews and meta-analyses of studies that evaluate healthcare interventions: explanation and elaboration," BMJ, vol. 339, no. jul21 1, p. b2700, 2009.

[27] G. H. Guyatt, A. D. Oxman, G. E. Vist et al., "GRADE: an emerging consensus on rating quality of evidence and strength of recommendations," BMJ, vol. 336, no. 7650, pp. 924-926, 2008.

[28] A. B. Gottlieb, P. J. Mease, B. Kirkham et al., "Secukinumab efficacy in psoriatic arthritis: machine learning and meta-analysis of Four Phase 3 Trials," Journal of clinical rheumatology : practical reports on rheumatic \& musculoskeletal diseases, 2020.

[29] I. E. Adamopoulos, C. C. Chao, R. Geissler et al., "Interleukin17A upregulates receptor activator of NF-kappaB on osteoclast precursors," Arthritis Research \& Therapy, vol. 12, no. 1, p. R29, 2010.

[30] B. Osta, F. Lavocat, A. Eljaafari, and P. Miossec, "Effects of interleukin-17A on osteogenic differentiation of isolated human mesenchymal stem cells," Frontiers in Immunology, vol. 5, 2014. 